\title{
Miniaturized High-Isolation Dual-Frequency Orthogonally Polarized Patch Antenna Using Compact Electromagnetic Bandgap Filters
}

\author{
Chunxia Cheng, Fushun Zhang, Yangtao Wan, and Fan Zhang \\ National Laboratory of Science and Technology on Antennas and Microwaves, Xidian University, Xian 710071, China \\ Correspondence should be addressed to Chunxia Cheng; cheng_chunxia@126.com
}

Received 25 December 2013; Revised 6 March 2014; Accepted 1 April 2014; Published 17 April 2014

Academic Editor: Michael Yan Wah Chia

Copyright (c) 2014 Chunxia Cheng et al. This is an open access article distributed under the Creative Commons Attribution License, which permits unrestricted use, distribution, and reproduction in any medium, provided the original work is properly cited.

A miniaturized dual-frequency dual-polarization microstrip patch antenna with high isolation between receiving and transmitting ports (operating at $2.1 \mathrm{GHz}$ for receiving and at $2.5 \mathrm{GHz}$ for transmitting) is presented in this paper. The proposed antenna consists of a modified rectangular radiating patch, two $50 \Omega$ microstrip feed lines, and two EBG filters. Two coupling microstrip lines are employed to excite two orthogonal fundamental modes $\left(\mathrm{TM}_{10}\right.$ and $\left.\mathrm{TM}_{01}\right)$. The high isolation is achieved by embedding two novel EBG filters underneath two feed lines to reject the incoming signal from the opposite line. Multilayer configuration, miniaturized EBG filters, and modified rectangular radiation patch contribute to size reduction. The total size is $0.67 \lambda \times 0.67 \lambda \times 0.03 \lambda$, only quarter of the multilayer rectangular radiation patch antenna $(1.33 \lambda \times 1.33 \lambda \times 0.03 \lambda)$ using common EBG filters with the same performance. Measured results on the reflection coefficients, isolations, and gains for the two frequencies are provided, which agree well with the numerical simulations. Also, measured isolations and radiation patterns at both two resonant frequencies are compared with the antenna without filters. The results show that the proposed method improves isolation by more than $20 \mathrm{~dB}$ with little influence on the radiation patterns.

\section{Introduction}

Dual-frequency dual-polarization antennas are often required for frequency reuse to enhance communication system capacities. The dual-frequency operation of the antennas can provide frequency diversity and dualpolarization operation can enhance the information content by providing two copolarization and two cross-polarization scatter data. For microstrip patch antennas, dual-frequency dual-polarization can be easily realized by using a pair of feeds to, respectively, excite two orthogonal fundamental modes from a single radiating patch; however, this type of antenna has a poor isolation between two exciting ports. To improve the port isolation, several studies have been done by employing different feeding structures [1-5]. In [1], port isolation levels in the range of $25 \mathrm{~dB}$ to $32 \mathrm{~dB}$ for each band were achieved by using a differential feeding mechanism. By placing defected ground structure (DGS) under the feed line, port isolation can be improved by $20 \mathrm{~dB}[2,3]$, but DGS suffer from increasing in back radiation. A shielding plane could be used to suppress the back radiation, although this could affect the antenna performance due to parallel plate modes propagation. Adding filter particles to the feeding structure is also a suitable method to increase the port isolation $[4,5]$. In [4], two filters based on electromagnetic bandgap structures (EBGs) have been investigated in order to increase the isolation. However, both filters are larger than $0.3 \lambda$. Moreover, both filters must be put $0.17 \lambda$ away from the radiation patch. Two filters based on spiral defected microstrip structures (DMS) are used to enhance the ports isolation [5]. Although both DMS filters are compact near $0.1 \lambda$, two quarter-wave-length transformers are needed to match the antenna impedance. So the total size of the DMS filter and the match particle is larger than $0.35 \lambda$.

There are two ways to solve the problem above: reduce the filter size or minimize the distance between the filter and patch. Structure miniaturization of EBG resonator is achieved practically by modifying via or the shape of the patch, such 
as edge-located via [6], etching CSRR on a conventional mushroom-type EBG [7]. For the purpose of further size reduction, etching dual U-shaped slots on symmetrically with respect to one axis of the edge-located vias mushroom-type EBG (DAU-EBG) is proposed [8]. Using multilayer structure and modified patch, the distance between the filter and patch can be reduced.

In this paper, a miniaturized dual-frequency dualpolarization microstrip patch antenna with high isolation is presented. A novel EBG filter with a compact size of $0.18 \lambda \times$ $0.06 \lambda$ is embedded underneath the feed line to enhance the isolation between receiving and transmitting ports. The isolation is improved by $20 \mathrm{~dB}$ compared to the antenna without filters. Moreover, using multilayer structure and removing four trapezoids from the four edges of the rectangular patch, the spaces between filters and patch edge are smaller than $0.02 \lambda$ for both ports. So the total size of the DEP-EBG filter and the spaces between filter and patch is smaller than $0.2 \lambda$. The total size of the proposed antenna is $0.67 \lambda \times 0.67 \lambda \times 0.03 \lambda$, which is smaller than that of the antenna $(1.33 \lambda \times 1.33 \lambda \times 0.03 \lambda)$ in $[4]$.

\section{Compact DEP-EBG Filter}

The conventional mushroom-type EBG (CMT-EBG), which is shown in Figure 1(a), can be characterized by an equivalent parallel LC resonator with a resonant frequency of $f_{r}=$ $1 / 2 \pi \sqrt{\mathrm{LC}}$. Compared with the CMT-EBG, the edge-located vias mushroom-type EBG (ELV-EBG) (Figure 1(b)) designed based on the concepts of LC resonator and $\lambda / 4$ horizontal corrugation soft surface [9] has a reduced size (with a limited miniaturization). For the purpose of further size reduction, a novel EBG is proposed. As shown in Figure 1(c) it is based on an ELV-EBG with dual E-shaped patch (DEP) symmetrically with respect to the $Y$-direction. As the DEP-EBG structure makes better use of the patch area to increase the current patch, the resonant frequency $\left(f_{r}\right)$, that is, the bandgap, is greatly brought down.

To quantitatively show the advantages of the proposed DEP-EBG structure, two filters consisting of three-cell DEPEBG that have the same stopband as [4] are designed and studied for comparison. Filter 1 has a stopband in the proximity of $2.5 \mathrm{GHz}\left(f_{1}\right)$ and filter 2 shows a stopband near $2.1 \mathrm{GHz}\left(f_{2}\right)$. Both filters are designed on a two-layer substrate with relative permittivity $\varepsilon_{r}=4.5$ and heights $h_{1}=0.4 \mathrm{~mm}$ $h_{2}=1.5 \mathrm{~mm}$ as shown in Figure 2. The $50 \Omega$ microstrip lines are $3.85 \mathrm{~mm}$ for both cases on the front surface of the twolayer substrate. The three-cell DEP-EBG filter is underneath the $50 \Omega$ microstrip line on the surface of the lower-layer substrate and the cell is connected to the ground plane through a via. The characteristics of the two filters have been calculated using HFSS 13 . The optimized parameters for filter 1 are $W=7.15 \mathrm{~mm}, L=6.5 \mathrm{~mm}, W_{0}=0.9 \mathrm{~mm}, W_{1}=$ $0.8 \mathrm{~mm}$, and $L_{1}=3.01 \mathrm{~mm}$ and for filter $2, W=8.4 \mathrm{~mm}, L=$ $8.7 \mathrm{~mm}, W_{0}=1.7 \mathrm{~mm}, W_{1}=0.92 \mathrm{~mm}$, and $L_{1}=3.92 \mathrm{~mm}$. The unit sizes of the reference CMT-EBG filters are $11.7 \mathrm{~mm}$ $\times 11.7 \mathrm{~mm}$ and $13.9 \mathrm{~mm} \times 13.9 \mathrm{~mm}$ for filter 1 and filter 2 , respectively. The gap between resonators is $g=0.5 \mathrm{~mm}$ and

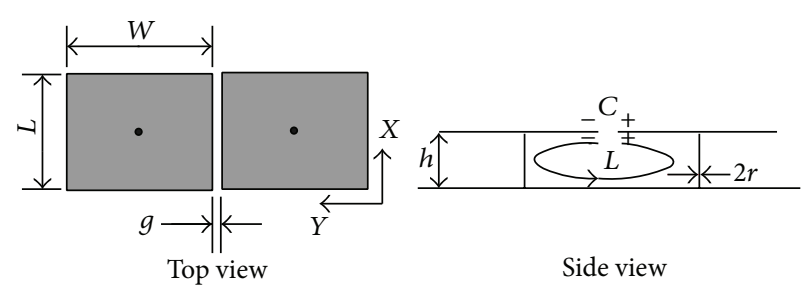

(a)

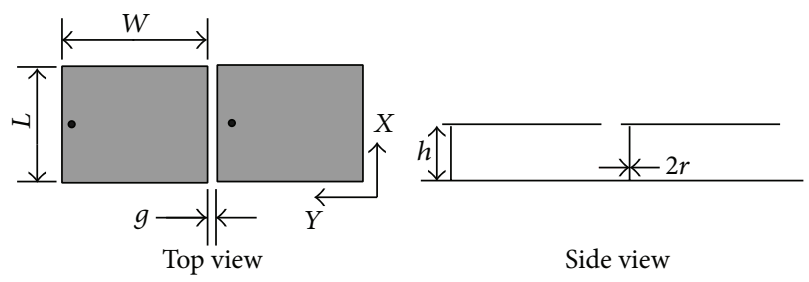

(b)

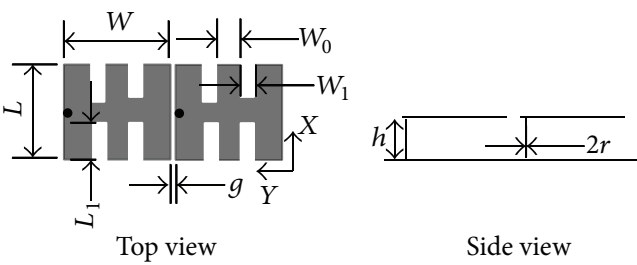

(c)

Figure 1: Geometries of the EBG. (a) CMT-EBG, (b) ELV-EBG, and (c) DEP-EBG.

the radius of via is $r=0.2 \mathrm{~mm}$ in all filters. So, the total sizes of the DEP-EBG filters are $0.16 \lambda_{1} \times 0.05 \lambda_{1}$ and $0.18 \lambda_{2} \times 0.06 \lambda_{2}$. While the sizes of the CMT-EBG filters are $0.30 \lambda_{1} \times 0.10 \lambda_{1}$ and $0.30 \lambda_{2} \times 0.10 \lambda_{2}$, the sizes of the DEP-EBG filters are only $53 \%$ and $60 \%$ of the reference CMT-EBG filters.

Figure 3 shows the simulated frequency response of the DEP-EBG filters compared with the reference CMT-EBG filters. The $2.1 \mathrm{GHz}$ CMT-EBG and DEP-EBG filters performances are $20 \mathrm{~dB}$ stopband: $5.71 \%$ and $3.62 \%$, minimum insertion loss in stopband: $-32 \mathrm{~dB}$ and $-31 \mathrm{~dB}$. The performances of both $2.5 \mathrm{GHz}$ filters are $20 \mathrm{~dB}$ stopband: $6.56 \%$ and $3.56 \%$, minimum insertion loss in stopband: $-32 \mathrm{~dB}$ and $-32 \mathrm{~dB}$. Although the $20 \mathrm{~dB}$ stopbands of DEP-EBG filters are narrower than CMT-EBG filters, they can be improved by increasing $h_{1}$. As shown in Figure 3 , when $h_{1}$ increases to $0.65 \mathrm{~mm}$ the $20 \mathrm{~dB}$ stopbands of $2.1 \mathrm{GHz}$ and $2.5 \mathrm{GHz}$ DEPEBG filters are $6.09 \%$ and $6.52 \%$, respectively.

\section{Compact High-Isolation Antenna}

The dual-frequency dual-polarization antenna with high isolation is designed to operate at $2.1 \mathrm{GHz}$ for port 1 and $2.5 \mathrm{GHz}$ for port 2 . The geometry of the proposed antenna is shown in Figure 4. This antenna is composed of a rectangular patch cutting off trapezoid in every side on the front surface of layer 3 , feeding lines on the front surface of layer 2, DEP-EBG filters on the front surface of layer 1 , and a conductor ground plane in the back of layer 1 . The antenna ground plane size is 


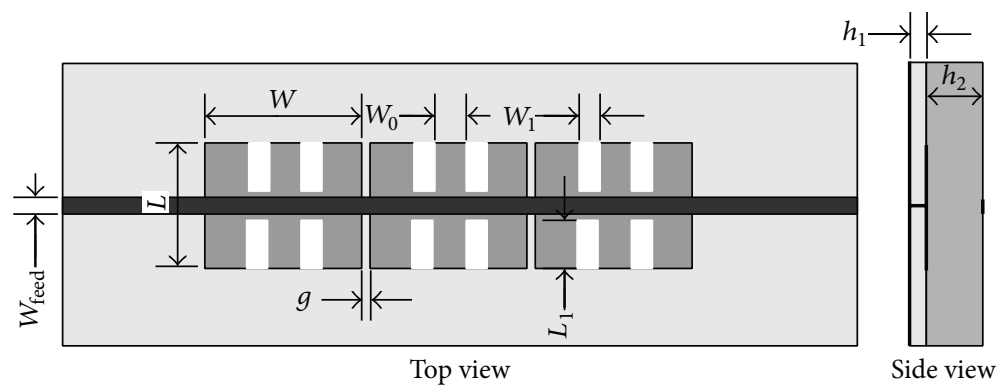

FIGURE 2: Figures of the three-cell DEP-EBG filters.

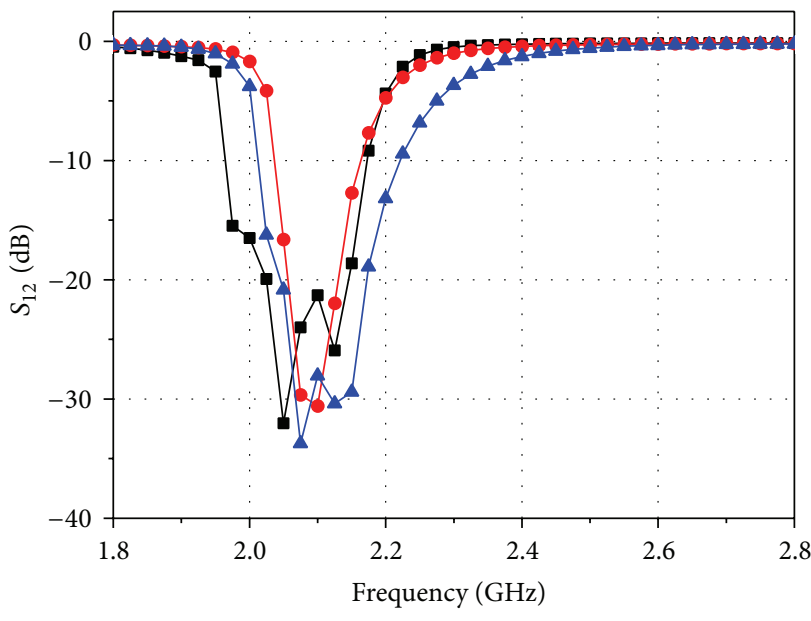

$\rightarrow-$ CMT-EBG filter, $h_{1}=0.4 \mathrm{~mm}$

$\longrightarrow$ DEP-EBG filter, $h_{1}=0.4 \mathrm{~mm}$

$\sim$ DEP-EBG filter, $h_{1}=0.65 \mathrm{~mm}$

(a) $2.1 \mathrm{GHz}$

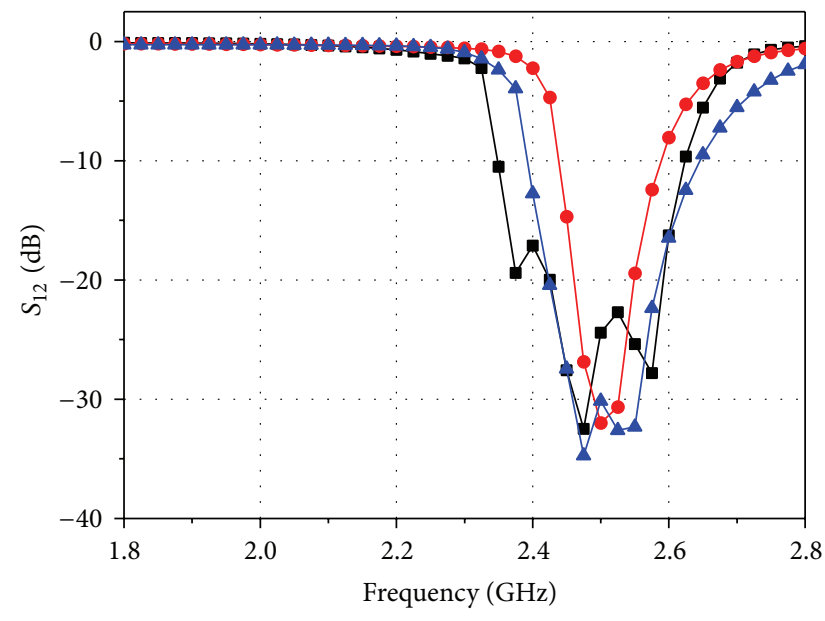

$\rightarrow$ CMT-EBG filter, $h_{1}=0.4 \mathrm{~mm}$

- DEP-EBG filter, $h_{1}=0.4 \mathrm{~mm}$

$\sim$ DEP-EBG filter, $h_{1}=0.65 \mathrm{~mm}$

(b) $2.5 \mathrm{GHz}$

FIGURE 3: Simulation results of the CMT-EBG and DEP-EBG filters.

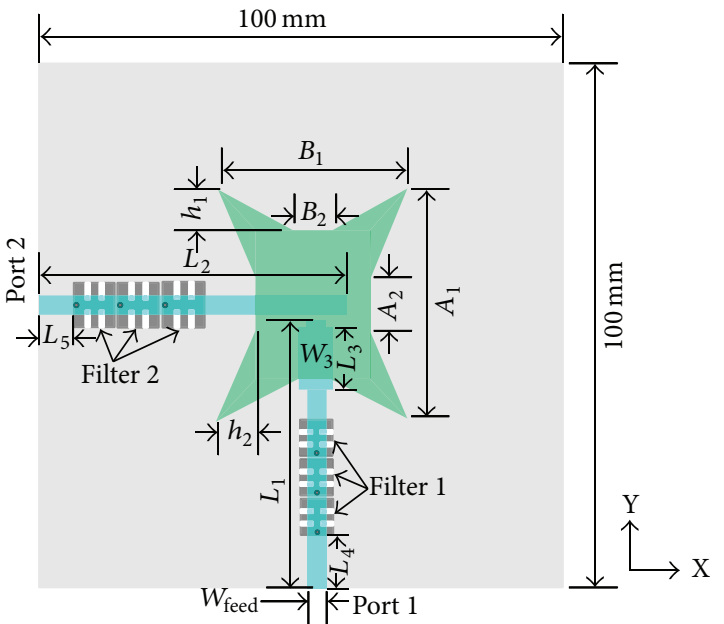

(a)

Layer $3, H_{3}=2 \mathrm{~mm}, \varepsilon_{r}=2.2$ Layer $2, H_{2}=1.5 \mathrm{~mm}, \varepsilon_{r}=4.5$ Layer $1, H_{1}=0.4 \mathrm{~mm}, \varepsilon_{r}=4.5$

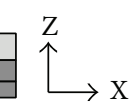

(b)

Figure 4: Configuration of the proposed antenna. (a) Top view. (b) Side view. 


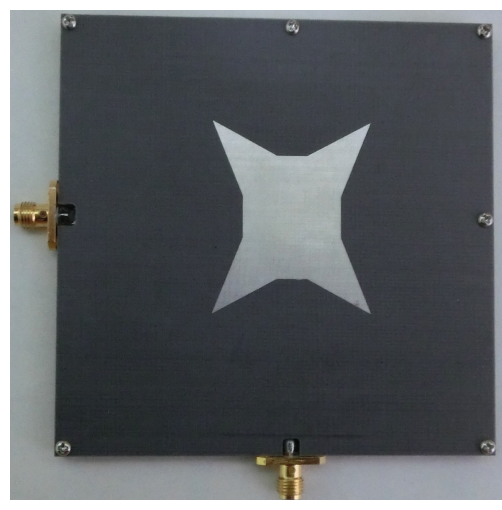

(a)

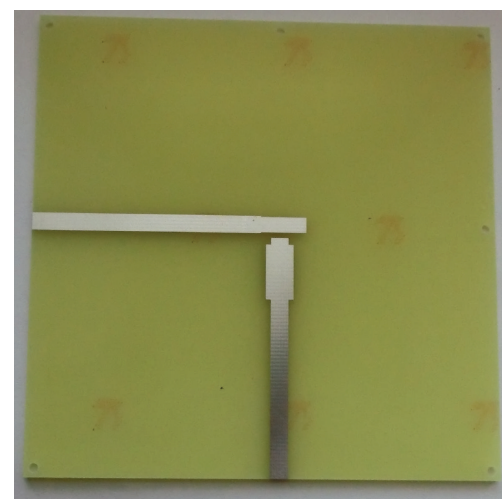

(b)

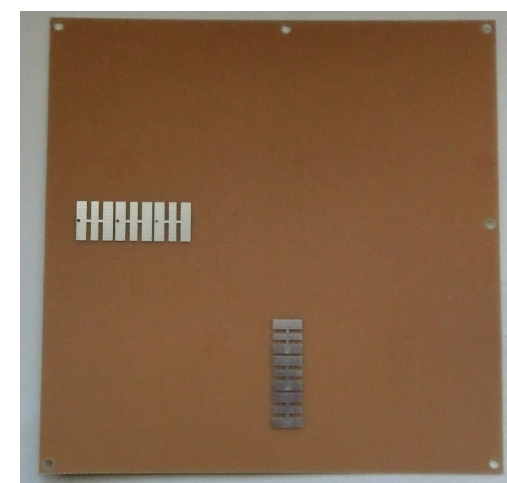

(c)

FIgURE 5: Photograph of the proposed antenna. (a) Top view of the antenna, (b) top view of the feed line, and (c) top view of the DEP-EBG.

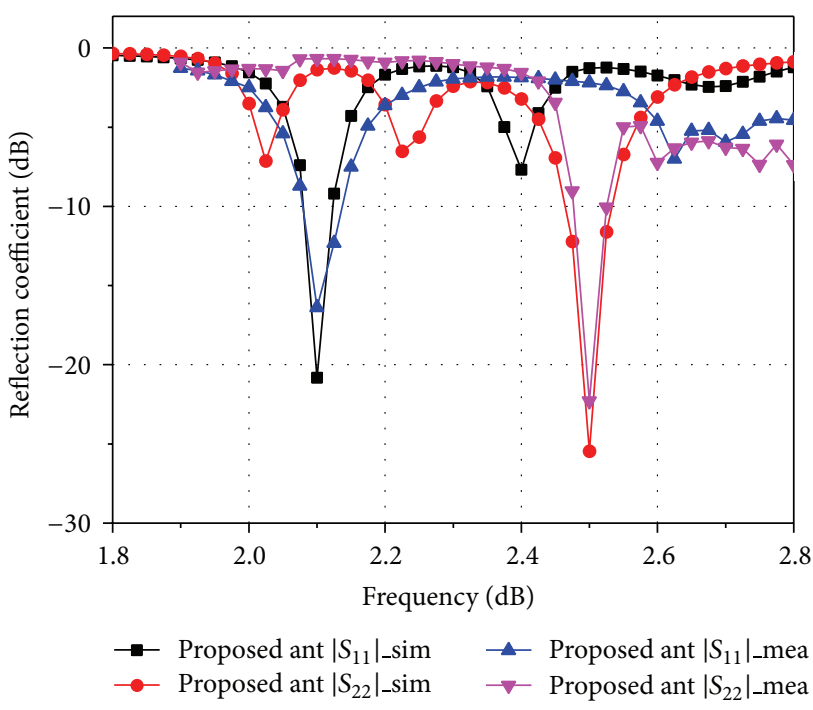

(a)

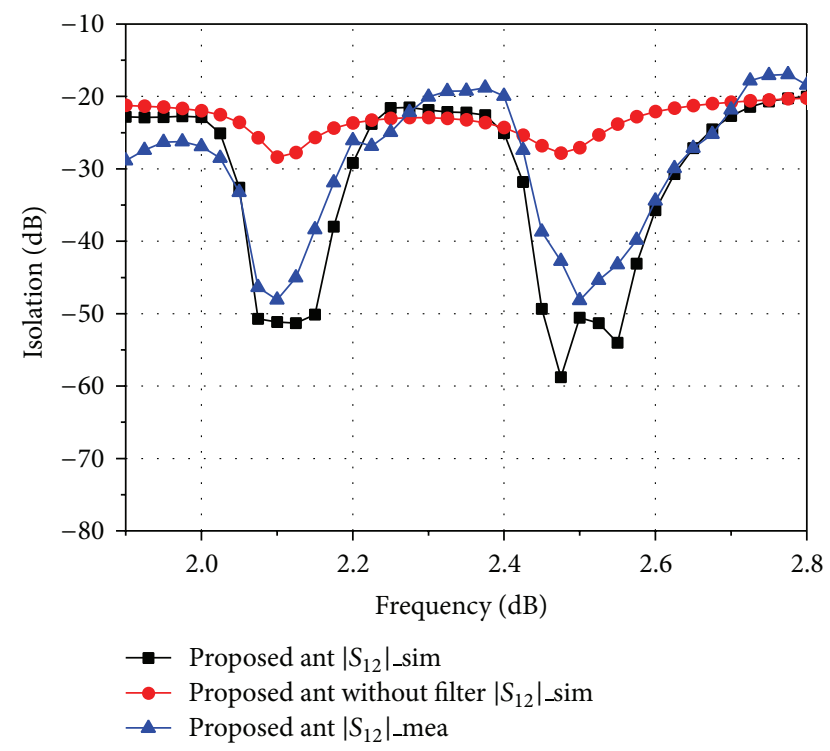

(b)

FIGURE 6: Measured and simulated $S$ parameters of DEP-EBG filters antenna. (a) Reflection coefficient. (b) Isolation.

$100 \times 100 \mathrm{~mm}^{2}$, which is only $25 \%$ of the reference antenna proposed in [4]. The modified rectangular patch dimensions are $A_{1}=44.3 \mathrm{~mm}$ and $B_{1}=36.5 \mathrm{~mm}$ and the trapezoids dimensions are $B_{2}=7 \mathrm{~mm}, h_{1}=8 \mathrm{~mm}, A_{2}=9.5 \mathrm{~mm}$, and $h_{2}=7 \mathrm{~mm}$. By removing four trapezoids from the four edges of the rectangular patch, the distances between the edge of filters and the vertex of patch are $-1 \mathrm{~mm}$ and $2.9 \mathrm{~mm}$ for filter 1 and filter 2 , respectively, smaller than $0.02 \lambda$. So a compact design is achieved. The width of $50 \Omega$ feed lines is $W_{\text {feed }}=$ $3.85 \mathrm{~mm}$ for both ports. The length of the horizontal feed line is $L_{2}=58.75 \mathrm{~mm}$ and the distance between port 2 and filter 2 is $L_{5}=6.85 \mathrm{~mm}$. The length of vertical feed line is $L_{1}=51.3 \mathrm{~mm}$ and the distance between port 1 and filter 1 is $L_{4}=9.58 \mathrm{~mm}$. The line-patch overlap of the horizontal feed line is larger than $B_{1} / 2$, and according to [4] port 2 is matching. Because both feed lines are in the same layer underneath the center of the patch, the length of the vertical feed line is shorter than $A_{1} / 2$ and port 1 does not match. So a simple matching network is added to the vertically feed line by modifying the width to $6 \mathrm{~mm}$ with a length of $12 \mathrm{~mm}$, and the distance between the modifying feed line and the open end is $1.5 \mathrm{~mm}$. Filter 2 is placed underneath the horizontal feed line to reject the input signal from port 1 and filter 1 underneath the vertical feed line to avoid propagation at the input signal from port 2 . The stopbands of filters are shifted due to the presence of the antenna, and by simply modifying the length $L_{1}$ to $2.94 \mathrm{~mm}$ and $4.03 \mathrm{~mm}$ and the length $W$ to $7.5 \mathrm{~mm}$ and $8 \mathrm{~mm}$ for filter 1 and filter 2 the stopbands move to $2.5 \mathrm{GHz}$ and $2.1 \mathrm{GHz}$. To validate our design, the compact high-isolation dual-frequency antenna is fabricated according to the previous parameters, as shown in Figure 5. The total size of the DEP-EBG filter antenna is only quarter of the CMT-EBG filter antenna in [4].

The measured and simulated $S$-parameter results of the two ports are depicted in Figure 6. It can be seen from Figure 6 that port 1 achieves $10 \mathrm{~dB}$ return loss bandwidth 


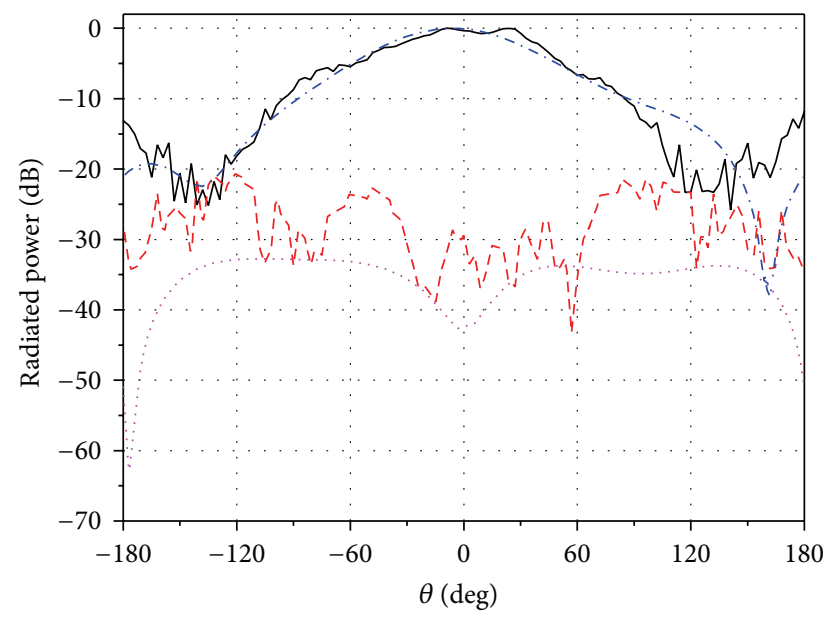

$\begin{array}{lll}\text { - Proposed ant_copolar } & -. \cdot- & \text { Antenna without filters_copolar } \\ \text { - - - Proposed ant_cross-polar } & \cdots . . . & \text { Antenna without filters_cross-polar }\end{array}$

(a)

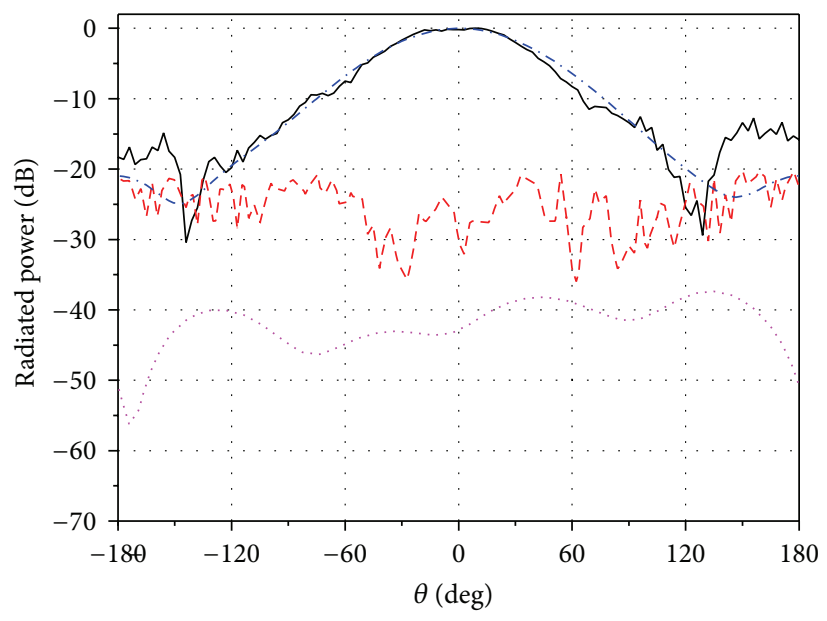

_ Proposed ant_copolar _..- Antenna without filters_copolar - - - Proposed ant_cross-polar …... Antenna without filters_cross-polar

(b)

FIGURE 7: Measured radiation pattern for port $1(2.1 \mathrm{GHz})$. (a) E-plane ( $y$ - $z$ plane), (b) H-plane ( $x$ - $z$ plane).

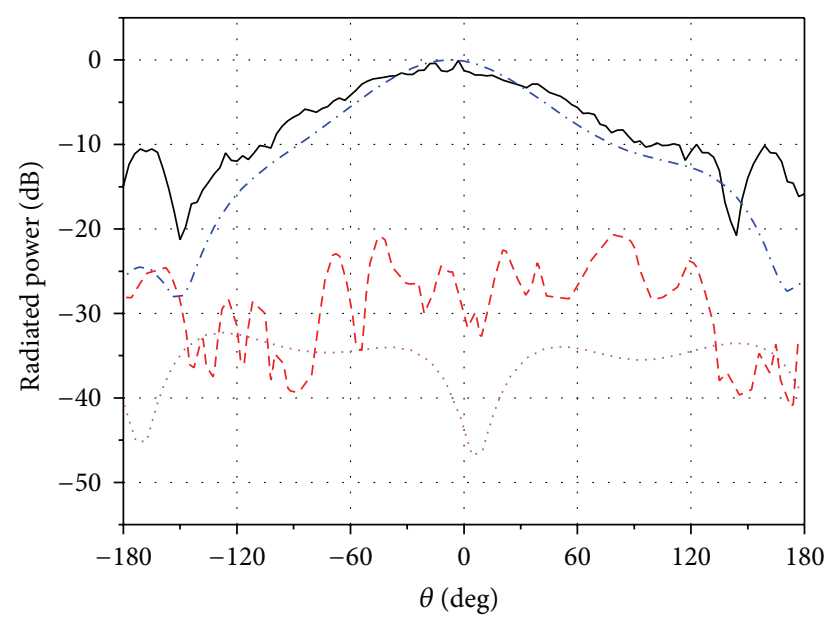

_ Proposed ant_copolar - - Proposed ant_cross-polar

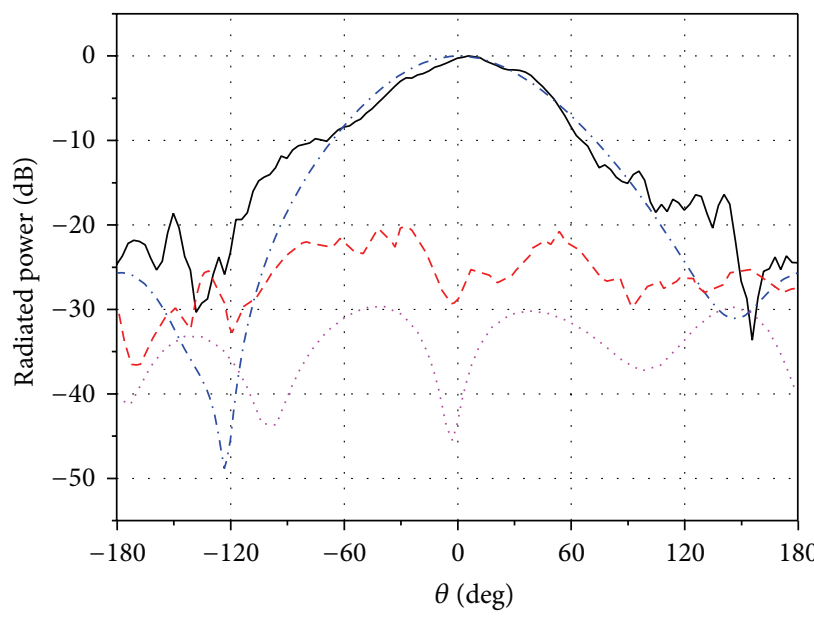

- Proposed ant_copolar - - - Proposed ant_cross-polar
-.- Antenna without filters_copolar Antenna without filters_cross-polar

(b)

FIgURE 8: Measured radiation pattern for port $2(2.5 \mathrm{GHz})$. (a) E-plane ( $x-z$ plane), (b) H-plane ( $y$ - $z$ plane).

around $2.14 \%(2.079-2.124 \mathrm{GHz})$ and port 2 around $2.84 \%$ $(2.463-2.534 \mathrm{GHz})$. More than $20 \mathrm{~dB}$ improvement in isolation between the two ports was obtained at the two frequency bands compared to the same antenna without filters, approaching minimum isolation around $48 \mathrm{~dB}$ within both bands in the DEP-EBG filters integrated antenna.

Figures 7 and 8 show the antenna radiation patterns in the E-plane and H-plane for the DEP-EBG filters integrated antennas and the same antenna without filters. The co- and cross-polarized radiation patterns in E-plane and $\mathrm{H}$-plane at both frequencies are shown. The antenna radiation patterns were measured with one port excitation and the other port connected to the matched load. It can be seen that the crosspolarization within the half-space above the ground plane remains less than $-20 \mathrm{~dB}$ in the two planes at both resonant frequencies. The radiation patterns are almost the same as for the same patch antenna without filters. As expected, the DEPEBG filters close to radiation patch do not affect the radiation properties of the proposed antenna.

The simulated and measured gains of the proposed antenna for the two ports are plotted in Figure 9. As seen, good agreement between simulation and measurement 


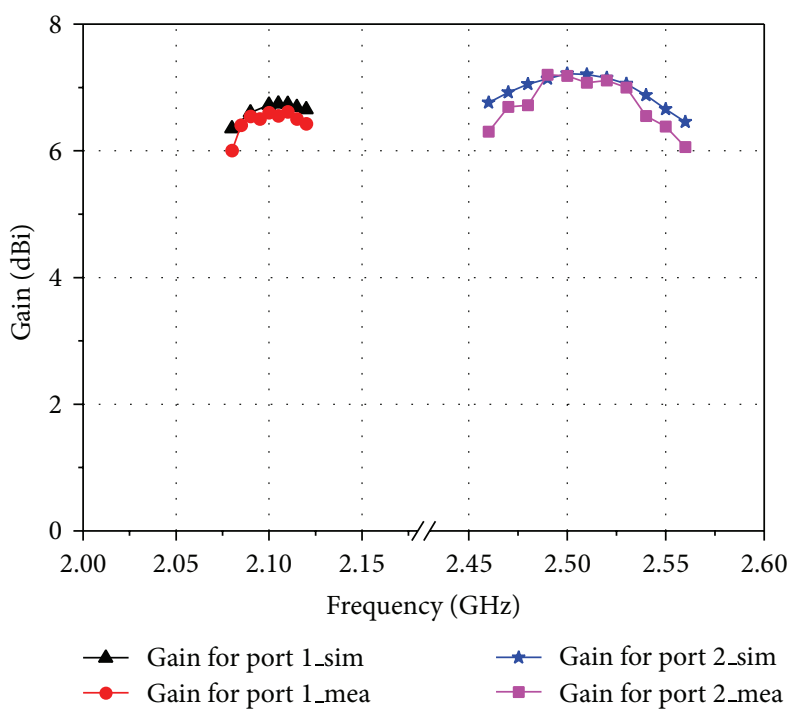

FIGURE 9: Measured and simulated gains of proposed antenna.

is observed. The obtained average gains are $6.46 \mathrm{dBi}$ and $6.85 \mathrm{dBi}$ within the 2.1 and $2.5 \mathrm{GHz}$ operating bands, respectively. It is clearly seen that the proposed antenna achieves stable gain within the two operating bands.

\section{Conclusion}

In this work, a compact dual-frequency dual-polarization antenna with high isolation has been successfully implemented and discussed. The high isolation is achieved by embedding two DEP-EBG filters underneath two feed lines to reject the incoming signal from the opposite line. The size of the compact DEP-EBG filters does not exceed $60 \%$ that of the CMT-EBG filters. By using a multilayer configuration, two compact DEP-EBG filters, and modified rectangular radiation patch, the size of the proposed antenna is only quarter that of the reference antenna in [4]. Measurement results show that the proposed method improves isolation to higher than $48 \mathrm{~dB}$ at both frequency bands. Furthermore, radiation patterns are almost not affected by the DEP-EBG filters close to the radiation patch. The simplicity and compactness of the design makes it desirable for practical application in dualfrequency dual-polarization communication systems.

\section{Conflict of Interests}

The authors declare that there is no conflict of interests regarding the publication of this paper.

\section{References}

[1] Z. Shi-Gang and C. Tan-Huat, "Dual-wideband, dual-polarized shared aperture antenna with high isolation and low crosspolarization," in Proceedings of the 10th International Symposium on Antennas, Propagation \& EM Theory (ISAPE '12), pp. 30-33, 2012.
[2] Y. Chung, S.-S. Jeon, D. Ahn, J.-I. Choi, and T. Itoh, "High isolation dual-polarized patch antenna using integrated defected ground structure," IEEE Microwave and Wireless Components Letters, vol. 14, no. 1, pp. 4-6, 2004.

[3] Y. Chung, S.-S. Jeon, S. Kim, D. Ahn, J.-I. Choi, and T. Itoh, "Multifunctional microstrip transmission lines integrated with defected ground structure for RF front-end application," IEEE Transactions on Microwave Theory and Techniques, vol. 52, no. 5, pp. 1425-1432, 2004.

[4] L. Inclan-Sanchez, J.-L. Vaquez-Roy, and E. Rajo-Iglesias, "High isolation proximity coupled multilayer patch antenna for dualfrequency operation," IEEE Transactions on Antennas and Propagation, vol. 56, no. 4, pp. 1180-1183, 2008.

[5] S. Fallahzadeh, H. Bahrami, A. Akbarzadeh, and M. Tayarani, "High-isolation dual-frequency operation patch antenna using spiral defected microstrip structure," IEEE Antennas and Wireless Propagation Letters, vol. 9, pp. 122-124, 2010.

[6] E. Rajo-Iglesias, L. Inclán-Sánchez, J.-L. Vázquez-Roy, and E. García-Muñoz, "Size reduction of mushroom-type EBG surfaces by using edge-located vias," IEEE Microwave and Wireless Components Letters, vol. 17, no. 9, pp. 670-672, 2007.

[7] L. Peng, C.-L. Ruan, and Z.-Q. Li, "A novel compact and polarization-dependent mushroom-type EBG using CSRR for dual/triple-band applications," IEEE Microwave and Wireless Components Letters, vol. 20, no. 9, pp. 489-491, 2010.

[8] L. Peng, C.-L. Ruan, and J. Xiong, "Compact EBG for multiband applications," IEEE Transactions on Antennas and Propagation, vol. 60, no. 9, pp. 4440-4444, 2012.

[9] E. Rajo-Iglesias, M. Caiazzo, L. Inclán-Sánchez, and P.-S. Kildal, "Comparison of bandgaps of mushroom-type EBG surface and corrugated and strip-type soft surfaces," IET Microwaves, Antennas and Propagation, vol. 1, no. 1, pp. 184-189, 2007. 

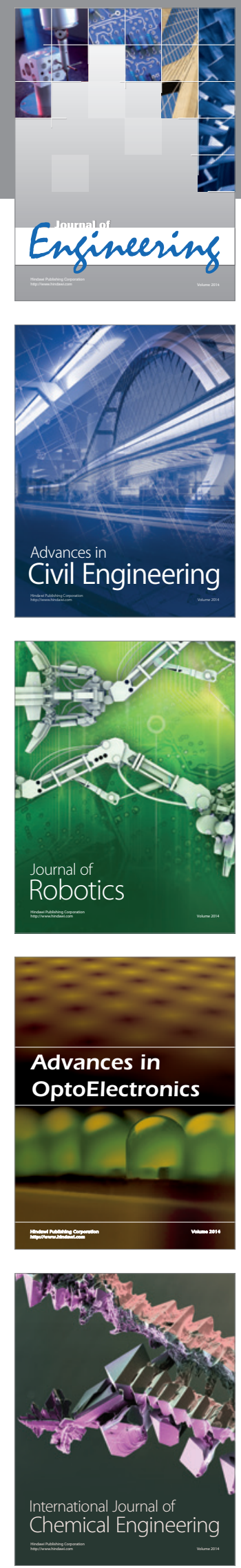

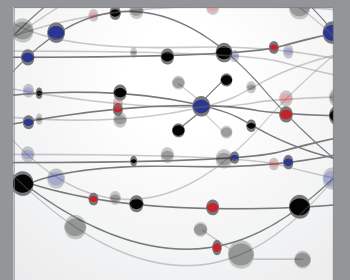

The Scientific World Journal
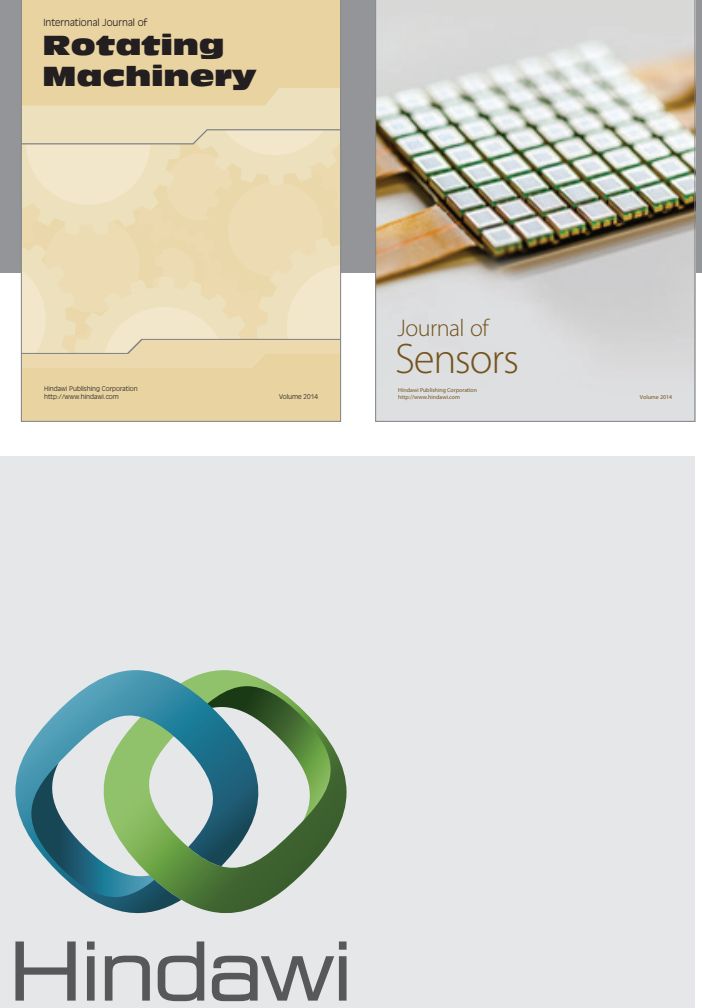

Submit your manuscripts at http://www.hindawi.com
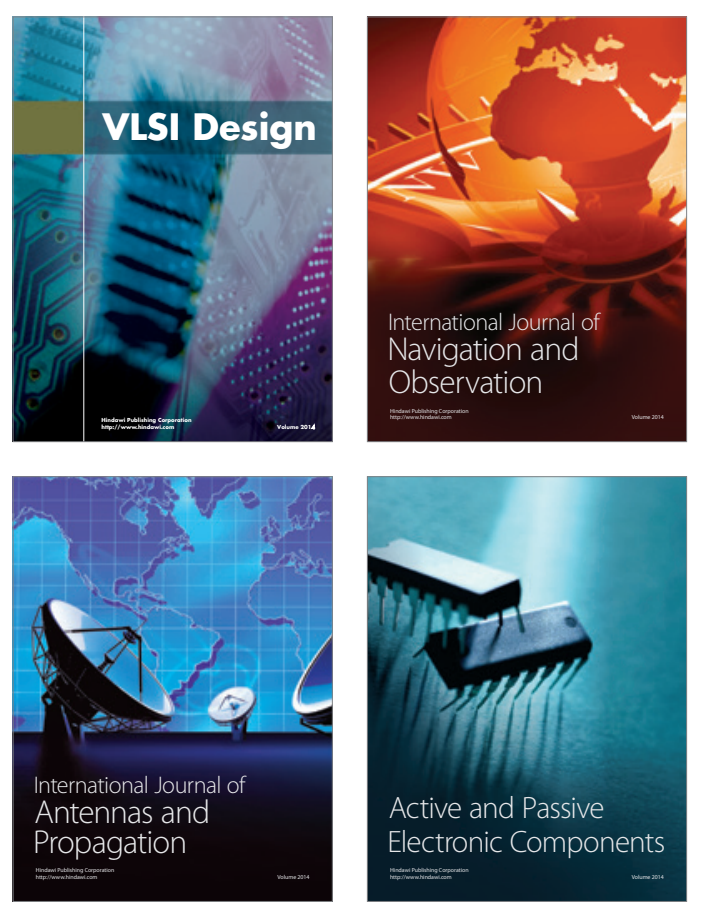
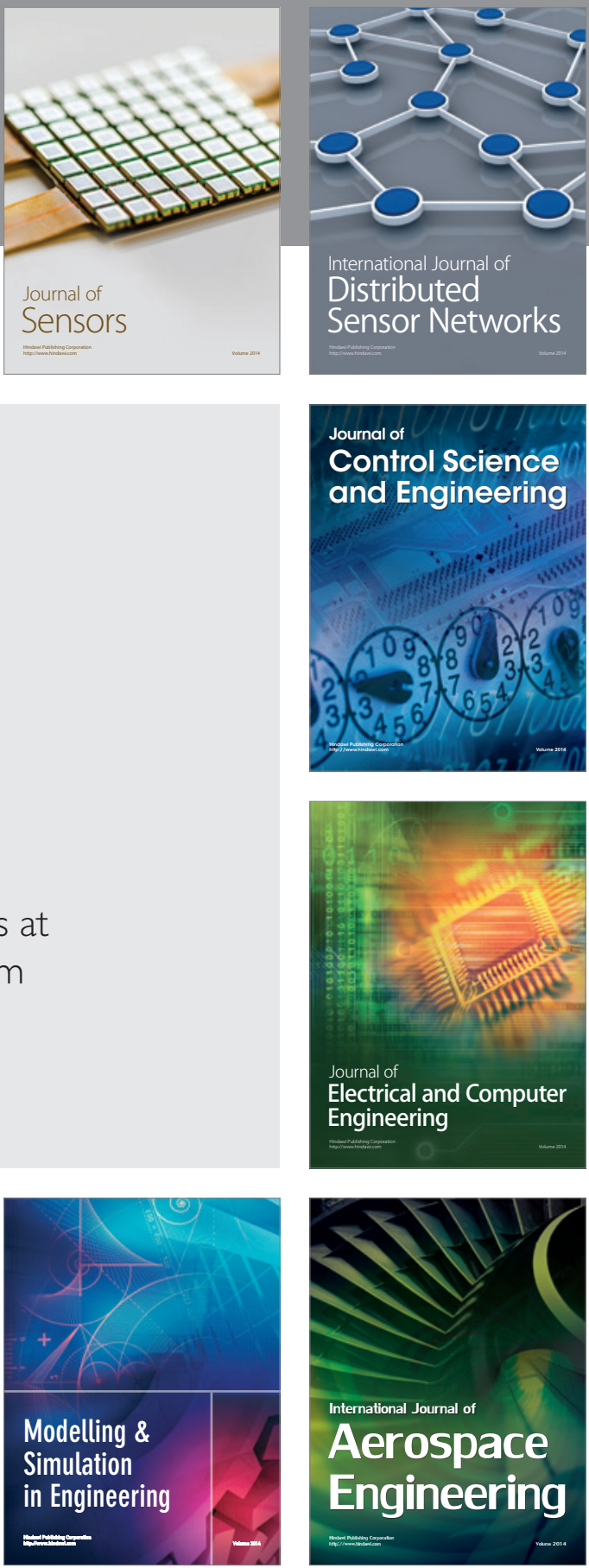

Journal of

Control Science

and Engineering
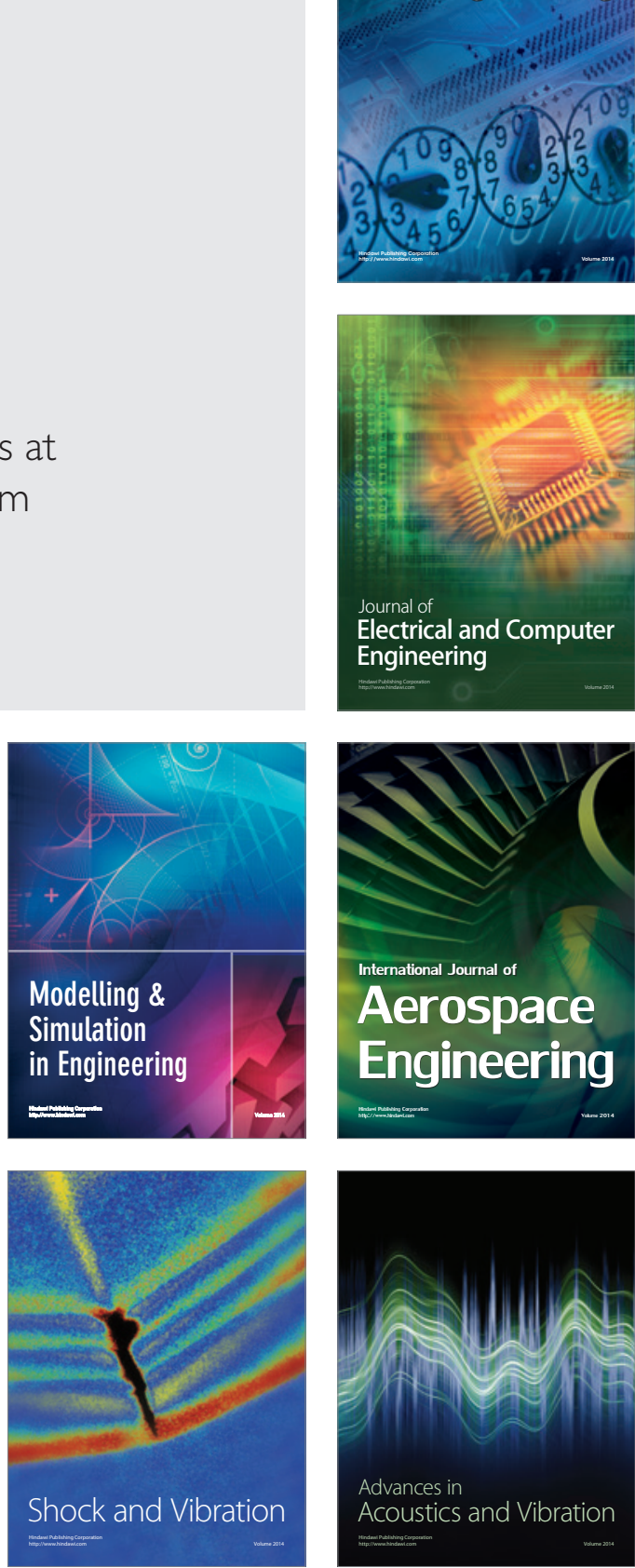